\title{
Deseos y Valores. El intelectualismo socrático y la tripartición del alma en la República
}

\section{(Desires and Values. Socratic intellectualism and the tripartion of the soul in the Republic)}

\author{
Álvaro VAllejo CAMPos
}

Recibido: 16 de julio de 2014

Aceptado: 23 de abril de 2015

\section{Resumen}

En la República Platón parece romper con el intelectualismo socrático al aceptar deseos independientes del bien. Sin embargo, esto no le impide seguir afirmando que el alma hace todo lo que hace en virtud del bien. Para resolver esta aparente contradicción en el presente artículo se insiste en la distinción entre deseos y valores. Los deseos, generados en las partes del alma, están apegados a sus objetos propios, pero los valores revisten estos deseos de imágenes del bien y otros elementos cognitivos que los convierten en móviles aceptables de la acción en la unidad del alma, por lo que hay que distinguir una volición independiente del bien en las partes del alma y una volición que actúa sub specie boni en el contexto de un alma unitaria que ha de decidir entre deseos opuestos entre sí.

Palabras clave: deseos, valores, intelectualismo, tripartición, voluntad.

\begin{abstract}
In the Republic Plato seems to abandon the Socratic intellectualism when he accepts the existence of desires that are independent of the good. Nevertheless, this does not prevent him from still affirming that "every soul pursues the good and for its sake does all that it does". In order to solve the apparent contradiction I propose in this article to distinguish between desires and values. The desires, generated by the parts of the soul, are closely attached to their proper objects, but the values add to them images of the good and other cognitive elements that transform the desires
\end{abstract}


into acceptable motives for action within the unity of the soul. Therefore I propose to distinguish between the wish of the parts and another kind of volition that operates in the unity of the soul sub specie boni in order to decide between opposed desires which compete with one another.

Keywords: desires, values, intellectualism, tripartion, will.

\section{Introducción. La tripartición del deseo y el principio de los opuestos}

Parece arriesgado hablar de una teoría platónica del alma, porque Platón nunca escribió un tratado sobre el alma, sino diálogos en los que se aborda el problema desde perspectivas muy diferentes, a veces aparentemente contradictorias. Me propongo examinar en este trabajo una aparente discrepancia entre dos líneas argumentativas que encontramos en los diálogos a propósito de la volición, porque creo que en la explicación de la aparente contradicción iluminaremos algunos aspectos muy interesantes de la teoría platónica del deseo.

En la República la teoría platónica del alma experimenta un giro que, a pesar de las coincidencias, parece un notable avance respecto al punto de vista excesivamente simple del Fedón. En esta última obra los deseos son explícitamente atribuidos al cuerpo (66c), aunque en otros momentos se hable de "un deseo (epithymía, 81e) de lo corpóreo" que acompaña al alma después de la muerte. Pero la cuestión es que el alma dialoga con los deseos como si estos fueran otra cosa distinta de ella misma (hōs állè oûsa dialegoménē, 94d).

Esta ambigüedad desaparece en la República, pues aquí el alma alberga ya en su interior con toda claridad elementos distintos de la mera inteligencia, mientras que en el Fedón el alma que está presta a partir en el momento de la muerte parece identificarse totalmente con ella y no consistir más que en razón (diánoia, 67c) purificada de toda contaminación pasional. Platón cita en ambos casos dos versos de la Odisea (XX 17-18) en los que Ulises se dirige a sí mismo.Sin embargo, la interpretación que se da en ambas obras de la misma cita es muy diferente, porque en el Fedón (94d) se toma como ejemplo de que el alma entra en conflicto con factores extraños a ella. En cambio, en la República las mismas palabras significan que hay "una especie de alma que censura a otra": uno es el elemento calculador, que "reflexiona acerca de lo mejor" y otro de naturaleza colérica que se "enardece irracionalmente" (IV 441c). En esta ocasión el diálogo del alma se ha convertido en un proceso interior en el que una parte de ella conversa consigo misma como una realidad compleja constituida por partes que colisionan y entran en conflicto mutuo. Ahora se interpreta el caso como una disputa de la razón con la cólera irreflexiva, mientras que en el episodio de Leoncio (Rep.439e-440a), que sucumbió a su deseo de ver 
los cuerpos ajusticiados, parecía tratarse de un conflicto en el que es precisamente el elemento colérico el que se opone al deseo concupiscible y lo censura cuando resulta finalmente satisfecho1.

El principio en el que se basa la tripartición del alma en la República tiene una formulación muy parecida al principio de no contradicción, aunque a mi juicio establece una verdad que es de una naturaleza diferente: "Es evidente que una misma cosa nunca producirá ni padecerá efectos contrarios en el mismo sentido, con respecto a lo mismo y al mismo tiempo. De modo que, si hallamos que sucede eso en la misma cosa, sabremos que no era una misma cosa sino más de una (436b-c)"2. Sócrates aplica este principio al alma, partiendo de deseos, como la sed y el hambre, y establece que el alma del que desea "tiende hacia aquello que apetece" (437c). Ahora bien, si en el mismo momento en que el alma experimenta este deseo que le lleva en dirección a la bebida o a la comida, algo la impulsa en otra dirección (439b), oponiéndose al deseo del alma sedienta, habría que concluir, en virtud del principio enunciado, que "hay algo en ella distinto de lo que le hace tener sed", pues "la misma cosa no obraría en forma contraria a la misma parte de sí misma, respecto de lo mismo y al mismo tiempo"3 (439b). Esta otra parte, responsable de originar un movimiento contrario al que la impulsa a beber, como Sócrates mismo se encarga de aclarar (439d), no es otra que el llamado razonamiento (logismós) o raciocinio (logistikón, 439d). Esta dualidad de motivos, generadores de impulsos contrarios, es el que conduce a la definición de dos especies (eídè, 439e) diferentes de alma, una racional y calculadora, y otra concupiscible. En el caso de Leoncio la dualidad, a juicio de Sócrates, se establece entre la parte colérica o irascible y la concupiscible, porque esta experimenta un deseo que arrastra a los ojos a satisfacerse con el espectáculo de los cuerpos ajusticiados, mientras que aquella quisiera contenerlo con un movimiento contrario, se enardece y toma parte en este combate que tiene lugar "cuando los deseos violentan a un hombre contra su raciocinio" (440b). Se concluye pues, sobre esta base de los conflictos psicológicos, que el alma está constituida por tres partes o géneros diferentes, caracterizados por deseos específicos.

Aunque muchos especialistas han afirmado que estamos ante la primera formulación del principio de no contradicción ${ }^{4}$, en mi opinión no se trata de un principio meramente formal que establezca una verdad tautológica, sino de un principio sin-

\footnotetext{
1 No está clara la naturaleza específica del deseo que tiene Leoncio de mirar los cuerpos. No parece de naturaleza sexual (cfr. Burnyeat, p.11 n.14), como ha negado con razón Ferrari, 2007, p.182, pero en cualquier caso es un deseo que le proporciona placer en contra de la razón (cfr. Cooper, 2001, p.101) y, probablemente, se trata de un deseo socialmente infamante (cfr., Vegetti, 1998, ad loc.), por lo que suscita la reacción airada del elemento colérico, que es sensible a las valoraciones sociales.

2 Cito la República, por la traducción de Eggers, 2012.

3 Propongo aquí para mayor exactitud una leve variación de la traducción de Eggers.

4 Véanse los comentarios a este pasaje en tres grandes ediciones de la República, como las de Adam, 1902, Shorey, 1969 o Vegetti, 1998.
} 
tético o empírico que pretende formular una verdad acerca del deseo y la motivación humana. No es un principio formulado solo para una aplicación estricta al ámbito teórico, en el que estuviéramos formulando una verdad lógica acerca de hechos, proposiciones o creencias, que nos prohibiera decir a la vez $\mathrm{p}$ y no $\mathrm{p}^{5}$, sino que se trata de aplicarlo a un dominio como el del "deseo y el querer" (tò ethélein kaì tò boúlesthai, 437b), que es donde entran en conflicto factores como los apetitos y los movimientos desencadenados por ellos. El principio de no contradicción tiene que ver con contradictorios y esto aplicado al caso que nos ocupa equivaldría a la imposibilidad de que un deseo se dé y no se dé al mismo tiempo en un mismo centro volitivo, pero en realidad Platón se refiere a contrarios (tanantía, 436b). Lo que el principio establece es que no es posible que un deseo se dé en una misma realidad y a la vez se dé otro que sea contrario a él, de ahí que otros especialistas prefieran llamarlo el principio de los opuestos, del conflicto o de la no oposición ${ }^{6}$. Es verdad que los contrarios pueden convertirse en contradictorios, dados determinados supuestos ontológicos, y el principio también puede aplicarse a ellos ${ }^{7}$, pero lo que quiero decir en resumidas cuentas es que para convertir la imposibilidad de la existencia simultánea de dos opuestos en un mismo principio volitivo en una contradicción flagrante necesitamos algo más que una mera interpretación formal del principio de no contradicción.

Platón no quiere negar simplemente que una misma parte del alma pueda tener y no tener un mismo deseo, sino que pueda tener un deseo y otro que sea contrario a este. Pero esto no es evidente sobre la base de un principio meramente formal. Tendríamos que demostrar que los deseos opuestos son tan incompatibles en la voluntad como los contradictorios lo son en realidad, pero esto es imposible sobre la base de una interpretación meramente formal del principio de no contradicción. Aunque Platón no haga distinción alguna, como es natural, entre un principio formal y una teoría apoyada en supuestos empíricos, sí que hace un esfuerzo por traducir el ámbito de los deseos a una dinámica volitiva formulada en términos de fuerzas y movimientos, con objeto de mostrar que los deseos contrarios son tan incompatibles en la voluntad como lo son la generación de dos fuerzas opuestas por parte de un mismo factor. De ahí que Platón traduzca el deseo en términos de una mecánica de fuerzas, en virtud de la cual el apetito en el alma equivale a "tender (ephiesthai) hacia aquello que apetece" o "atraer (proságesthai) hacia sí aquello que

\footnotetext{
5 El principio de no contradicción en la formulación aristotélica afirma que "no es posible que lo mismo se dé y no se dé en lo mismo a la vez y en el mismo sentido" (Metafísica IV 3, 1005b19-20). Como nos indica T.Calvo en la nota a su traducción del pasaje, en Aristóteles el principio tampoco es meramente lógico ni ontológicamente neutral.

6 Cfr., por ejemplo, Crombie, 1979, I, p. 366, Robinson, 1971, p. 39, Irwin, 1977, p. 327, Stalley, p.110, Annas, 1981, p. 137, Miller, 1999, p. 92.

${ }^{7}$ Cfr. Aristóteles, Metafísica, IV 3, 1005 b27 y Refutaciones Sofisticas, 180a26. Cfr. Vallejo 2013, 192198.
} 
quiere" (437c). De la misma manera "no querer" (abouleîn), "no desear" (mē ethélein) y "no apetecer" (mēd'epithymeîn) son entendidos en términos mecánicos de "rechazar" (apōtheîn) y "alejar (apelaúnein) del alma" (437c). Con esta traducción de los motivos psicológicos volitivos a fuerzas físicas ${ }^{8}$, hemos dejado de hablar en términos de querer y odiar, que era posible a la vez en el famoso verso de Catulo, para hacerlo en términos de pulsiones dinámicas opuestas, como atraer y rechazar, que son dos acciones que no pueden ser realizadas a la vez por una fuerza respecto a lo mismo9. Esta traducción de lo anímico volitivo a una teoría del movimiento y sus fuerzas impulsoras no debe ocultarnos que estamos ante dos órdenes diferentes. Desear algo y desear a la vez otra cosa opuesta a la primera no registra el grado de incompatibilidad que tiene en el ámbito del movimiento la atracción y repulsión ejercidas por una misma fuerza.

Pero no se trata de mostrar las insuficiencias en su formulación del principio, sino de extraer consecuencias acerca de su modo de comprender el funcionamiento de la volición. Pues de toda esta discusión quedan en claro importantes observaciones sobre esta cuestión. En primer lugar, a juicio de Platón, la coexistencia de dos deseos contrarios es incompatible en un mismo centro volitivo. Todo su esfuerzo teórico parece ir encaminado en su teoría del deseo a convertir la coexistencia de la contrariedad en una imposibilidad del mismo rango que la contradicción. En segundo lugar, Platón no parece distinguir en relación con ello entre el funcionamiento de las partes intelectivas y volitivas del alma, ya que asimila a este efecto los deseos a opiniones, de manera que, igual que una misma parte no puede tener deseos contrarios entre sí, tampoco puede albergar opiniones opuestas. Esto es explícitamente afirmado en el libro VI cuando Platón distingue, en relación con las artes imitativas, entre una facultad razonadora (logistikón, 602e), que "mide, cuenta y pesa", y una parte inferior que opina "al margen de la medición" (parà tà metrá, 603a). La discrepancia de opiniones se da en el alma cuando esta es víctima de una ilusión de los sentidos y se le aparecen las cosas curvas o cóncavas en lugar de rectas y convexas, es decir, bajo una apariencia contraria a la opinión que se forma a la vez gracias a su capacidad de medida y cálculo racional (cfr.602c-d). Se tiene que aplicar aquí el mismo principio que opera en el caso del deseo y, en consecuencia, Sócrates establece, recordando los pasajes correspondientes del libro IV, que "es imposible para la misma parte del alma emitir a la vez opiniones contrarias sobre lo mismo" (602e). La imposibilidad de la coexistencia de contrarios impera por tanto de la misma manera en la esfera teórica que en la práctica y en ambos casos conduce a la necesidad de distinguir entre centros volitivos e intelectivos diferentes.

\footnotetext{
8 Cfr. Miller, 1999, p. 94.

9 Como ha indicado Price, 1995, p. 41, "pushing and pulling are more opposed than contrary desires".
} 


\section{El deseo y las partes del alma}

La aplicación de este principio, que prohíbe en la volición la coexistencia de deseos opuestos, conduce a la tripartición platónica del alma, lo cual equivale, efectivamente, a una concepción tripartita del deseo. Cada parte del alma, la racional o calculadora, la colérica o irascible y la concupiscible son caracterizadas, desde el punto de vista del conflicto psicológico estudiado en la República, por contener deseos específicos y propios que pueden entrar en colisión con los deseos de las demás. La parte apetitiva o concupiscible (epithymētikón) está dominada por la pasión sexual y el deseo de beber o comer (439d, 580e) u otros de esta naturaleza. Otras veces es caracterizada como ávida o amante de las riquezas (philochrếmaton, 442a, 580e-581a, 582a-b), porque "es a través del dinero como se satisfacen los apetitos de esta índole" (580e). En segundo lugar, los deseos propios de la parte colérica tienen que ver por entero con "el predominio, la victoria y el renombre" (581a, cfr.545a, 548c, 582e, 586c). De ahí que Platón la llame "ambiciosa" o "amante del triunfo" (philónikon) y "amante de honores" (philótimon, 581b). La parte racional también tiene un deseo y un placer que le es propio (580d): aquello "con lo que aprendemos o conocemos la verdad" experimenta un deseo que le hace ser "amante de aprender" (philomathés) o "amante del conocimiento" (philósophon, $581 b)$.

Es una indicación más de lo que venimos diciendo acerca de la indistinción entre lo teórico y lo práctico, pues Platón caracteriza esta parte racional del alma tanto por su capacidad para "conocer la verdad" como por el deseo intrínseco que posee de alcanzar el saber (581b) ${ }^{10}$. Platón atribuye, efectivamente, deseos a la parte calculadora. El predominio de uno de los tres tipos de deseos sobre los demás permite hablar de tres géneros de vida, según estén centradas en la tendencia (el conocimiento, la victoria y la ganancia) que caracteriza a cada una de las tres partes del alma. La existencia de una vida propiamente "filosófica" se deriva tanto del propio ejercicio de la racionalidad como de la persecución del placer que esta parte encuentra al seguir el deseo que le es propio (581c).

Lo que se trata de ver es si esta complejidad de motivaciones que es reconocida con toda claridad en la República supone una ruptura de principio con el intelectualismo socrático de diálogos anteriores. La cuestión es si estos deseos son independientes del bien. Platón parece afirmarlo así, al examinar el deseo de beber y su potencialidad para oponerse a otros principios presentes en el alma que le impidan satisfacerlo (439b). Sócrates pone el dedo en la llaga al decir que no debemos dejarnos desorientar por alguien que venga a afirmar que "nadie desea bebida, sino buena bebida, ni una comida sino una buena comida, dado que todos apetecen cosas

10 Cfr. Kahn, 1987, p.80. La concepción platónica de la razón como una forma de deseo, dice Kahn, es tan poco familiar para nosotros que podría parecer una especie de error categorial. 
buenas" (438a). Lo que este texto indica con claridad es que la sed es un deseo de bebida que debe ser concebido como tal simpliciter, es decir, sin ninguna cualificación que lo relacione a priori en sí mismo con el bien ${ }^{11}$. De ahí su potencial para entrar en colisión con otras motivaciones que sí estén abiertas a ese tipo de consideraciones.

Para mostrar el potencial conflictivo de los deseos, Platón los incluye en el género de las cosas correlativas: estas están enlazadas de tal modo entre sí que las unas están referidas a las otras independientemente de cualquier otra consideración 12 . Se trata de cosas que están conectadas exclusivamente entre sí, de modo tal que "están referidas solo a esas otras cosas en sí mismas" (438d). La sed, por ejemplo, es un deseo que remite a la bebida como su correlato primario e incondicionado. El que tiene sed o hambre desea beber o comer y no beber o comer algo, porque esto sea bueno y todos deseen lo bueno. Esta inclusión del deseo dentro del género de los correlativos, en el que se enlazan parejas como lo mayor con lo menor, el doble con la mitad, lo pesado con lo liviano, lo rápido con lo lento, pero también la sed con la bebida y el hambre con la comida, evita una interferencia del bien en la generación del deseo, que en principio puede surgir así, por sí mismo, sin relación intrínseca con otra cosa que no sea su objeto intencional. El hambre está referida a la comida y la sed a la bebida sin más. De ahí que algunos autores hayan sostenido que Platón está abandonando el principio socrático, defendido en diálogos anteriores, de que "todas nuestras acciones intencionales se apoyan en nuestro deseo del bien"13. Sin embargo, a mi juicio, si Platón sigue afirmando la tesis socrática de que todos los hombres desean el bien, la concepción del deseo que acabamos de ver podría ser compatible con ella y eso es lo que deberíamos esforzarnos por entender. Pero antes debemos ocuparnos de hasta dónde llega la autonomía de las partes del alma.

La existencia de partes diferentes en el alma está basada en la defensa del principio de los opuestos, referido a la existencia de deseos potencialmente independientes del bien. Pero la cuestión es qué son las partes del alma cuya existencia se afirma sobre esta base, porque Platón no aclara en la República ni en otros diálogos cuál es su status ontológico. Solo incidentalmente utiliza el término "parte" (méros, Rep.442b-c, 444b) y, como otros especialistas han señalado ${ }^{14}$, utiliza varios tipos de

11 Cfr. en este sentido Penner, 1978, p.107.

12 Es lo que Delcomminette ha llamado la "determinación recíproca de los correlativos", 2008, p.9.

13 Cfr. Irwin, 2000, p. 349 y Penner, loc. cit. Lorenz, 2006, pp.29-30. Para la tesis socrática de que todos los hombres desean el bien, cfr. Gorgias 467d-468c y Menón 77e-78b. Del Banquete hablaré más adelante.

14 Como ha indicado Robinson, 1971, p.46, Platón evita cualquier sustantivo que describa la clase de entidad que está intentando descubrir en el alma. Cfr. también Shields, 2001, p. 156, n.24. Fronterotta ha indicado que el uso de esta palabra (méros) aparece en contextos en los que las partes del alma se comparan con las partes de la ciudad previamente identificadas, por lo que atribuye el uso del término a la transferencia a la psicología de la terminología política (2013, p. 169 n.5). 
expresiones, como un artículo con una cláusula relativa o un dativo instrumental ("aquello con lo que razona", "aquello con lo que ama", 439d) y otros nombres, como especies (eidê, 435c-e, 436a, 437c-d, 439e, 440e, 504a, 580d, etc.) y géneros (genê, 441c, 443d, ), para evitar tener que pronunciarse acerca de esta cuestión de un modo más preciso y definido.

Se ha discutido si hay que concebir las partes del alma como "los sujetos últimos de afecciones psicológicas, actividades y capacidades que atribuimos normalmente a la persona como un todo" 15 o se trata más bien de "aspectos de nosotros mismos...que tienden a entrar en conflicto", como una mera "sede de deseos y creencias"16. La evidencia textual (Rep. IV 436-439) no es determinante y ya hemos visto que el lenguaje mismo utilizado por Platón parece no querer zanjar la cuestión desde un punto de vista ontológico preciso. Nosotros no vamos a resolver esta cuestión, pero, para comprender cómo operan los deseos en el alma, sí conviene preguntarse hasta dónde llega la autonomía de las partes. A mi juicio se trata de una autonomía limitada, que debe ser compatible con la unidad del alma, a la vista de la clara evidencia textual que podemos encontrar a favor de esta. Si la concepción de las partes como sujetos últimos de pleno derecho nos condujera a negar la unidad del alma y nos obligara a afirmar que Platón niega "la unidad de la persona" o la existencia de "un único sujeto último de todos los estados y actividades psíquicos de una persona" 17 , creo que sería una buena razón para rechazarla, porque la complejidad de elementos que componen el alma no le impide referirse a esta como un todo con una vida anímica compartida de la que participan a la vez las distintas especies o géneros de la teoría tripartita.

Cuando se establece la existencia de las tres partes, estas actúan entre sí sin perder de vista "al alma íntegra" (hypèr hapásēs tês psychês, 442b6): este es el horizonte común que deben contemplar las partes, tanto cuando lo racional delibera acerca de lo que conviene más, como cuando lo irascible moviliza las energías necesarias para asegurar el cumplimiento de lo que debe hacerse. Platón habla, en efecto, de divergencias o "partes" en el alma, de una forma tal que obliga a reconocer sujetos diferentes del deseo, pero esto no significa que se pierda de vista "la comunidad (hólōi tôi koinôi , 442c7) que integran las tres partes". En otras ocasiones, refiriéndose al proceso educativo que puede sacar al hombre de la caverna, dice que hay que sustraerse a lo que tiene génesis "con toda el alma" (syn hólè têi psychêi, $518 \mathrm{c} 8$ ). Cuando en el libro IX compara al alma con una especie de animal mitoló-

\footnotetext{
15 Bobonich, 2002, p. 219; véase también Lorenz, 2006, p. 23.

16 La primera cita es de Price, 2009, p. 1 y la segunda pertenece a otra obra del mismo autor, 1995, p.53.

${ }^{17} \mathrm{Al}$ menos en la versión de Bobonich, para quien la teoría partitiva de la República obligaría a Platón "a negar la unidad de la persona" (2002, p. 254), a diferencia de lo que sostiene Lorenz (2006, p. 26 n.18, y 2004, p. 94 n. 22).
} 
gico en el que se combinan "una bestia polícroma y policéfala" (lo concupiscible) con un "león" (lo irascible) y un hombre interior (la razón), esta perspectiva no olvida que las tres figuras se deben combinar en una sola (eis hén, 588d7) y que todas ellas deben ser criadas y educadas de tal manera que sean "amigas entre sí" $(589 b)^{18}$. Aunque Platón pueda dejar en el aire la precisión ontológica que hubiéramos deseado acerca de la relación entre las partes y la totalidad del alma, es evidente que esta amistad y esta concordia, en la que viene a consistir (cfr.442c-d) la moderación, presupone la unidad del alma como el espacio común en el que puede tener lugar dicho acuerdo.

"Resulta difícil" decidir, dice Sócrates (436a), si "en todos los casos actuamos por medio de un mismo género, o bien, si por ser tres los géneros, en un caso obramos por medio de uno de ellos, en otro por medio de otro" (436a). Platón parece optar desde perspectivas distintas por las dos opciones contempladas en este texto, pero a primera vista la aplicación del principio de los opuestos que viene a continuación (436b y sgs.) supone aceptar tres factores diferentes, desencadenantes de deseos que pueden entrar en conflicto. Por medio de ellos "somos fogosos" (thymoúmetha, 436a), "deseamos los placeres" (epithymoûmen ...hèdonôn), o aprendemos (manthánomen) y ponemos en marcha motivaciones de carácter intelectual con la independencia necesaria para aplicar el principio de los opuestos. A primera vista parece establecer la tripartición en el sentido fuerte de atribuir sujetos distintos a los deseos incompatibles que colisionan entre sí, pero la mereología en favor de la cual parece decantarse el texto a mi juicio está circunscrita específicamente a la motivación: ¿actuamos con cada una de las partes o "es que procedemos por medio del alma íntegra cuando nos ponemos en acción (ormếsōmen, 436b)"? Este pasaje, que nos lleva a la tripartición, está referido especialmente a la motivación: no se trata a mi juicio de saber si en las actividades anímicas en general actuamos siempre por medio de las partes o implicando a toda el alma, sino de dilucidar cómo actuamos "cuando nos ponemos en acción", es decir, cuando nos sentimos impelidos a obrar sometidos a la fuerza motivadora del deseo ${ }^{19}$. Sin embargo, a la vista de otras actividades del alma, no podríamos excluir la segunda opción contemplada y, en efecto, hay ocasiones en las cuales operamos "por medio del alma íntegra" (holêi têi psychêi, 436b). Son operaciones en la que está implicada la unidad del alma: las tres

\footnotetext{
18 Migliori (2013, pp. 747 y sgs.) indica con razón que a propósito del alma Platón utiliza diversos modelos, un modelo unitario, pero también uno binario, que distingue entre naturaleza mortal e inmortal, y un modelo ternario, como en el Fedro o la República.

19 Lorenz reconoce (2006, p. 20), después de citar el texto (436a8-b4), que se trata de cuestiones específicas relacionadas con la motivación, pero a su juicio esto no conduce a concebir las partes como tendencias de un alma unitaria sino a un idea del alma "como un compuesto de una pluralidad de partes" (p. 22). Como hemos visto, Lorenz concibe las partes como "sujetos o portadores de diferentes clases de condiciones motivadoras" de un modo que hace del alma una entidad compuesta (cfr. pp. 35 y sgs.).
} 
partes constituyen un todo en común (hólōi tôi koinôi, 442c7) y participan precisamente por ello del ordenamiento unitario que hace posible la existencia de un alma justa. La moderación implica "la amistad y la concordia de las partes" que exige "estar de acuerdo" (homodoxôsi, 442d1) acerca de quién debe gobernar. Solo así, a partir de la pluralidad de elementos, constituida por las tres partes del alma (443d3), se puede llegar a la "unidad absoluta (pantápasin héna, 443e1) a partir de la multiplicidad". Sin ánimo de zanjar la cuestión acerca del estatuto ontológico de las partes y del tipo de entidad que corresponde a esta unidad, propia del alma justa y ordenada, lo que pretendo subrayar es que todos estos textos, que vienen a complementar la tripartición con la perspectiva de la unidad, hablan en favor de una vida anímica que no puede ser concebida como una mera relación atómica de elementos independientes. Es innegable que las partes tienen una conciencia común, aunque se trate de deseos y motivaciones opuestas, de ahí que este hecho se haya considerado un obstáculo central para la concepción de las partes como sujetos psicológicos distintos 20 .

Si recordamos la imagen del carro alado en el Fedro (253d y sgs.), esta describe los comportamientos divergentes que suscita la contemplación del amado por parte del amante en el auriga y los dos caballos, pero aquí también se habla de la vida en común que comparten estos tres elementos e incluso del diálogo que se establece entre ellos. El caballo negro de lo concupiscible quiere saltar sobre el amado, pero no puede hacerlo solo. Su disputa con el otro caballo y con el auriga es la muestra más evidente de la limitada autonomía que tienen las partes respecto a la unidad del alma que Platón nunca deja de lado. La independencia de lo concupiscible viene determinada por la pertenencia del deseo al género de los correlativos: busca sin más la satisfacción sexual del deseo, porque el amor comporta para él la atracción irresistible de la carne más allá de todo principio ético. Sin embargo, para satisfacer el deseo, ha de concurrir en disputa con las otras partes que esgrimen consideraciones muy distintas. Vemos cómo el caballo concupiscible forcejea con ellas y les obliga a acercarse al amado, "para suscitar el recuerdo del placer sexual" (254a). Si ellos se resisten y pretenden dejarlo para más adelante, pero dejan pasar mucho tiempo, él se lo "recuerda" (254d) y quiere acercarse al amado. Unas veces el auriga consigue contenerlo y acaba dominándolo con el miedo, pero otras veces, cuando está junto al amado, el "caballo desenfrenado del amante tiene algo que decir al auriga" (255e). A veces consigue sus propósitos y ocasionalmente vuelve a dar rienda suelta a su satisfacción carnal, pero no a menudo, "puesto que están haciendo algo que no parece bien a la totalidad de la mente (pásēi dianoíai, 256c).

Es posible que de la naturaleza alegórica del episodio haya que descartar muchos detalles derivados de la imagen plástica del auriga y los caballos. Pero a mi juicio la contemplación del amado y las turbulencias ocasionadas entre las partes

20 Cfr. Price, 2009, p. 10. 
del alma pone de manifiesto varias cosas. En primer lugar, cada parte experimenta deseos específicos y da cabida a tendencias diversas que van desde el deseo más descarnadamente sexual a la vergüenza o la veneración y el respeto. Pero, en segundo lugar, las partes no pueden actuar por sí solas, sino en la mutua interacción que decide finalmente el curso de la acción. Observemos también que la parte concupiscible puede exponer sus "razones" (254d6) tanto al objeto de su deseo como al propio auriga que se había negado a concederle la satisfacción inmediata de su impulso. Esto significa, en tercer lugar, que la parte concupiscible puede utilizar recursos cognitivos que están a su disposición en la unidad del alma de la que ella también participa. La imagen en mi opinión pone de relieve que no estamos ante tres sujetos psicológicos independientes, sino ante tres fuentes motivacionales distintas que habitan dentro de "un todo en común". Aunque Platón dice en la República que la parte concupiscible es irracional (alógistos, 439d7), también la llama, como hemos visto, "ávida de riquezas". Esto significa a mi juicio que la parte concupiscible, aunque esté determinada por el placer de forma más o menos inmediata, es capaz de apropiarse de elementos cognitivos suficientes para comprender que "es a través del dinero como se satisfacen los apetitos de esta índole" (580e). Aunque algunos insisten en su irracionalidad absoluta y su incapacidad consiguiente para formular razonamientos de medio a fin ${ }^{21}$, no veo cómo puede desear la parte concupiscible el dinero, en lugar del mero y puro placer inmediato, sin participar al menos de una racionalidad estratégica elemental que le permita comprender la relación de una cosa con la otra 22 . Esto significa que las partes no son sujetos aislados, sino acciones que participan de recursos comunes disponibles en la unidad del alma de la que forman parte.

Pero observemos también la distinción introducida en el Fedro entre la motivación carnal de la parte concupiscible y la desaprobación de "la totalidad de la mente" que viene a censurarla. Cuando se da la armonía moral de una personalidad integrada, el alma exhibe una "unidad absoluta, moderada y armónica", como se dice en la República (443e). En los casos en los que prevalece la virtud moral es cuando más resplandece esta unidad, que es algo más que la mera suma de las partes: la justicia significa que en el interior del alma el sujeto moral "ha de disponer bien lo que es suyo propio... y se autogobernará, poniéndose en orden a sí mismo con amor y armonizando sus tres especies simplemente como los tres términos de la escala musical" (443d). Como vemos, en la personalidad justa es donde mejor se pone de manifiesto este sujeto único, que logra ser amigo de sí mismo (phílon geno-

21 Cfr. Lorenz, 2008, p.261. Sin embargo, véase, en contra de ello, Bobonich, 2002, p. 244. Sobre la existencia de elementos cognitivos en las tres partes, véase Kahn, 1987, pág. 85.

22 A juicio de Lorenz el deseo del dinero en la parte concupiscible no depende de una comprensión racional de una relación de medio a fin, sino que se trataría de una valoración directa del dinero en sí mismo por obra de lo concupiscible, lo cual me parece muy difícil de aceptar (cfr. 2004, pág. 111). 
ménon heautôi, 443d5) imponiendo un orden y una armonía en las partes, como si estuviera dotado de una unidad independiente de ellas que no se reduce a la mera suma de estas 23 . Por otra parte, la concepción del alma como una entidad única no está ausente en otros diálogos de Platón. En el Teeteto hay un conocido pasaje (184d) en el que Sócrates hace ver a su interlocutor que los sentidos no son aquello "con lo que vemos y oímos", sino que deben ser concebidos más bien como instrumentos "por medio de los cuales" realizamos estas operaciones de la sensibilidad cuyas informaciones "confluyen en una única entidad (eis mían tína idéan, 184d3), ya sea el alma o como haya que llamarla" 24 .

La autonomía de las partes parece limitada al deseo, porque desde este punto de vista el principio de los opuestos no admite un mismo centro capaz de experimentar a la vez deseos contrarios entre sí. Pero los deseos no pueden lograr su satisfacción inmediata sin hacer valer sus derechos en la unidad del alma en la que están integradas las partes. Por otra parte, el ejemplo del arquero (Rep. 439b), según el cual aquel rechaza el arco con una mano y la atrae con la otra, pero no con las dos al mismo tiempo, no puede aplicarse al alma literalmente, sino mutatis mutandis, porque el alma no ocupa espacio 25 y sus "partes" no pueden concebirse como cosas materiales sin relación entre sí. En resumen, las partes son autónomas a la hora de generar deseos específicos de cada una de ellas, pero forman parte de una unidad funcional, que es dentro de la que tienen que actuar.

\section{La unidad del alma y la voluntad: la diferencia entre deseos y valores}

Con esta conclusión estamos en disposición de afrontar la cuestión a la que me refería anteriormente de si la concepción del deseo sostenida en la República es compatible con la posición socrática que atribuye al hombre un deseo genérico del bien. Aunque la tesis se encuentra en otros diálogos ${ }^{26}$, en el Banquete hallamos una

\footnotetext{
23 Esto no significa que la tripartición sea solo el resultado de una personalidad moralmente imperfecta. A pesar de que el libro X parece decantarse por una esencia unitaria del alma basada en la razón (cfr. 611e), en su condición terrena la tripartición parece constituir para el Sócrates de la República, como ha visto C. Gill, "una caracterización válida de la naturaleza humana" (2013, p. 167). Insistiendo precisamente en la unidad del alma, Rowe ha defendido que la tripartición no debe interpretarse como la forma preferida de describirla que Platón tiene cuando escribió la República (cfr. 2011, 225-231).

24 Price $(2009$, p.8), a la vista de este texto, sostiene que el pasaje de la República (436a) en el que parece rechazarse la implicación total del alma podría entenderse en el sentido de que el alma hace tales cosas (desear, encolerizarse, aprender) como un todo, aunque las hace cualificadamente en un aspecto de sí misma. A juicio de P. Natorp, un pasaje como el del Teeteto revela claramente "la unidad de la consciencia como función fundamental del conocimiento" $(1999, \mathrm{p} .145)$.

25 Como nos recordaba Robinson, a propósito del significado de las partes del alma, 1971, p.38.

26 Cfr. Menón 77e-78b, Gorgias 467d y sgs.
} 
exposición particularmente interesante relacionada con la teoría platónica del amor. Sócrates protesta contra el significado particular que asocia la palabra érōs con determinados deseos de una naturaleza específicamente sexual y propone comprenderlo a la luz de una concepción genérica del deseo en virtud de la cual deberíamos entender por amor "todo deseo de lo bueno" (205d2). En este sentido genérico el amor expresa una dinámica de la volición, que consiste siempre en un deseo del bien (206a3). Platón utiliza indistintamente diversas palabras como epithymía (200e4, 205d2, 207a7), boúlēsis (205a5) y erōs (200e5, 205a5, 207a7) o los correspondientes verbos epithymeîn $(200 \mathrm{a} 3,202 \mathrm{~d} 2$, etc.), boúlesthai (205a2-3) y erân (205b2) para significar que es una ley invariable de la volición desear el bien o el objeto que se propone bajo la apariencia del bien. En mi opinión, aunque no tiene una palabra específica para ello, en estos textos del Simposio se está apuntando a la noción de voluntad como algo que va más allá del mero concepto de deseo. S.Tomás, que tiene ya un concepto claro de la voluntas, dirá en esta línea que "el amor es el primer movimiento de la voluntad" y que "el bien, en sí mismo y principalmente, es el objeto de la voluntad y del apetito" (S.T. 1a, 20,1).

A través de su concepción del amor a mi juicio Platón está comenzando a alumbrar la idea que conducirá a una concepción genérica de la voluntad como deseo del bien. Cuando digo genérica, quiero hacer referencia a dos aspectos diferentes. En primer lugar, es genérica, porque es una forma de la volición que es atribuida a toda la humanidad (cfr. Banq.205a5 y sgs.): se trata de algo "común a todos los hombres". Todos los hombres desean poseer el bien, dice Diotima (205a9-11). Pero, en segundo lugar, es genérica en otro sentido, porque querer bajo la forma del bien no es sólo una propiedad de la parte racional del alma cuando apetece el objeto que le es propio, sino que los objetos de las demás partes también pueden ser apetecidos bajo idéntica formalidad. En el texto del Simposio al que me refiero, el amor, entendido en esta segunda acepción de lo genérico, como "deseo (epithymía) del bien y de ser feliz" (205d2), es reconocido como tal en tres ámbitos diferentes, pues afirma Sócrates que unos lo buscan "en los negocios (katà chrēmastismón), otros a través de su afición a la gimnasia (katá philogymnastían) y otros en fin por medio de su amor a la sabiduría (katà philosophían, 204d4-5)". En la interpretación que propongo de este texto, considero que estos tres campos de acción son una referencia a los objetos propios de las tres partes del alma, que serán analizadas en la República. El bien y la felicidad, son perseguidos de diferentes maneras y una de éstas es la búsqueda del dinero: se busca el bien y la felicidad por medio de los negocios (205d4). El bien al que aspira la volición aparece como dinero, un deseo que la teoría tripartita del alma en la República atribuye, como hemos visto, a la parte apetitiva e irracional (cfr.580e5). En segundo lugar, el texto hace referencia a las competiciones atléticas como un segundo camino bajo el que se busca el bien y la felicidad. La palabra en cuestión (philogymnastía) y sus derivados significan 
amar los ejercicios gimnásticos. Lo que impulsa a los hombres que buscan el bien de esta forma no es el deseo de ganar dinero, sino el amor a la victoria y el honor (philotimía, philonikía), que son precisamente la dinámica a la que responde la parte colérica del alma (cfr. Rep. 586c9, 582e4-5, 548c7, 545a3). El hombre en el que predomina lo colérico es un amante del honor que considera "el placer que deriva del dinero como vulgar y bajo" (581d5). Esta clase de personas, destinados a la clase militar en el estado ideal, es muy sensible a los placeres que se originan con "el predominio, la victoria y el renombre" (581b2). Se trata de objetivos fácilmente asequibles con la práctica de la gimnástica y el deporte, y, de hecho, Platón atribuye al hombre timocrático, "debido a la prevalencia de la fogosidad" (548c), esta misma devoción por la gimnástica (philogymnastés, 549a6) referida en el Banquete. De manera que este segundo motivo, mencionado en esta última obra, a través del cual muchos buscan el bien, lo interpreto como una clara referencia a la parte colérica del alma en la psicología tripartita de la República.

En tercer lugar, nuestro texto menciona el amor a la sabiduría, que representa el impulso dominante en la parte racional del alma (cfr.Rep. 611e) e, igualmente, el objetivo principal del tipo de hombre que elige una vida dedicada a la búsqueda de la verdad. El amante de aprender y del saber (philomathés, philósophon, Rep.581b9), aludido en el texto del Banquete, conforma un tipo de vida en la que el bien y la felicidad es buscada bajo la forma del conocimiento y de los placeres que derivan de él. El texto habla en mi opinión, por consiguiente, de una forma única bajo la cual la voluntad se orienta al bien y a la búsqueda de la felicidad, pero a través de tres diferentes maneras, que aluden a los impulsos dominantes de las partes del alma, distinguidas como tales en la República, y a la existencia de las tres clases de hombres, de acuerdo con la motivación fundamental de sus vidas: "la vida del filósofo o la vida del amante del saber, el amante de la victoria y el amante del lucro" (Rep. 581c). Desde este punto de vista, no veo ninguna diferencia en Platón entre una facultad racional de la voluntad y una facultad irracional del deseo, en el sentido de que también los objetos apetecidos por las partes irracionales pueden revestirse de una apariencia del bien que les hace ser aptos como objetos de este éros o de esta boúlēsis de la que nos habla el Banquete 27.

Sin embargo, si volvemos a la República y atendemos a esa concepción del deseo que ubica a este en el género de los correlativos, donde está vinculado con un objeto propio con independencia del bien, parece que se hubiera abandonado la posición socrática establecida en diálogos como el Banquete ${ }^{28}$. Pero el deseo genérico del bien, que hemos examinado en esta última obra, para sorpresa de los intérpretes, volvemos a encontrarlo en la República. Efectivamente, después de haber

27 Sobre estas apariencias del bien con las que pueden revestirse los objetos del deseo de las otras partes del alma, cfr. Vallejo, 2009, 113-136 y 2011, 299-306.

28 Véase anteriormente la nota 13. 
expuesto en el libro IV la teoría de la tripartición y la clasificación del deseo dentro del género de los correlativos, en el libro VI, a la hora de tratar del bien, Sócrates vuelve a afirmar aquella misma tesis del Banquete cuando dice que el bien es "lo que toda alma persigue y por lo cual hace todo, adivinando que existe, pero sumida en dificultades frente a eso y sin poder captar suficientemente qué es" (505d-e). Se han hecho varios intentos de interpretar este texto para reconciliarlo con la existencia de deseos que son independientes del bien. Uno de estos consiste en limitar el alcance de la expresión "toda alma" (hápasa psychế), que querría decir no el alma en su integridad, sino cada una de las almas 29 , o lo que es lo mismo, cada alma solo en tanto que es racional ${ }^{30}$ y tiene como tal una "conexión natural con el bien". El inconveniente de esta posición es que el texto dice que el alma hace todo lo que hace en virtud del bien (toútou héneka pánta práttei, 505d-e), y no solamente las cosas que hace la parte racional del alma. En consecuencia, se ha intentado otra interpretación que pretende disolver la contradicción entendiendo la expresión "todo lo que hace" de otra manera, que da lugar a la siguiente traducción: el bien es "lo que toda alma persigue y aquello en lo cual pone todo su empeño"31. De esta manera tendríamos un reconocimiento de la incontinencia en el libro IV, con la tripartición del alma y la posibilidad de que el deseo del bien pueda ser vencido por otros deseos, y una afirmación, contenida en esta frase del libro VI, en virtud de la cual Sócrates, contra lo sostenido en diálogos anteriores, estaría reconociendo que el alma hace un gran esfuerzo en aras del bien aun cuando no siempre consigue que triunfe ese propósito. Se reconciliarían así las afirmaciones de ambos libros. Aunque la razón aspira al bien y, en unas condiciones normales, triunfa sobre deseos que tienen una orientación diferente, nada impediría que sea vencida por lo irracional que se alberga en nuestro interior. Por tanto, el Sócrates de la República habría abandonado en puridad la tesis intelectualista de acuerdo con la cual la virtud consiste en el conocimiento y el mal es debido a la ignorancia, porque se admitiría la posibilidad de deseos que son capaces de sobreponerse al conocimiento del bien.

\footnotetext{
29 Rowe, 2007, p.52, n.30. Para Rowe, "es en virtud de la conexión natural de la razón con el bien por lo que "toda alma" (no el alma en su integridad) ... hace todo lo que puede en aras del bien".

30 Cfr. Kahn, 1987, p.89. El significado de la frase en cuestión ("lo que toda alma persigue...") para Kahn sería el siguiente: "el bien es lo que todos queremos en la medida en que somos racionales".

31 Véase en este sentido la propuesta de Irwin, 1977, p.336, n.45. Una traducción parecida a la ofrecida por Irwin ("goes to all lengths") puede encontrarse en otras versiones, como la italiana de F. Gabrieli ("...per cui fa ogni sforzo") o la alemana de W. Wiegand (“... und dessentwegen sie alle Anstrengungen unternimmt”), citadas en su análisis del pasaje por Ferber (2013, pág. 234). Esta versión, como indicaba Irwin, locus cit., permitiría después de todo la existencia de la incontinencia. Pueden verse diversas variantes de esta interpretación, que pretende reconciliar la tripartición del libro IV con esta tesis acerca del bien como objeto de la aspiración genérica del alma, por ejemplo, en Rowe, 2005, p. 211 y sgs. y Burnyeat, 2006, p.14.
} 
Es muy posible que el intelectualismo socrático haya experimentado en la República notables variaciones, como es el caso de admitir en el tejido social una virtud como la valentía, que, en la clase de los guerreros, no puede estar basada en el conocimiento, sino en "una opinión engendrada por la ley" (429c)32. Pero la traducción alternativa ofrecida del pasaje en cuestión, que pretende abrir un espacio al reconocimiento de la incontinencia, oculta el hecho de que las demás partes del alma, a pesar de su irracionalidad, también consiguen revestirse de apariencias del bien que hacen admisibles sus deseos en el conflicto de motivaciones que tiene lugar en el interior de la vida anímica. A mi juicio la solución que permite compatibilizar el alma tripartita y el hecho de que el bien sea para el alma aquello que ella siempre persigue y en virtud de lo cual hace todo lo que hace es la distinción entre deseos y valores que encontramos en numerosos pasajes de la República.

Las partes son independientes y autónomas en lo relativo a la generación de deseos, que pueden ser independientes del bien y tener una base meramente fisiológica. Pero esto no significa que su papel en la economía del alma se reduzca a oponerse al bien ${ }^{33}$, porque los deseos, para buscar su satisfacción, tienen que actuar en la unidad del alma y son capaces de revestirse de imágenes o apariencias del bien que les permita triunfar en su competencia con los demás. Esta capacidad de los deseos para ser más que meras fuerzas irracionales, ciegas en la búsqueda de su satisfacción, se ve en aquellos pasajes de la República en los que Platón habla de los conflictos entre las diversas partes del alma. En el caso del hombre que acaba por imperar en el régimen democrático, fuertes y numerosos deseos de naturaleza concupiscible se apoderan de la "acrópolis del alma del joven" (Rep. 560b). Según se dice, faltan en este puesto de mando "conocimientos, preocupaciones rectas y discursos verdaderos" (560b8-9) y "en vez de ellos, corren al asalto discursos y opiniones (lógoi te kaì dóxai) falsas y petulantes, que ocupan su lugar" (560c2-3). Estos discursos y opiniones, que acompañan a los deseos, son su contrapartida cognitiva y axiológica para revestirse de una apariencia del bien que les permita "prevalecer en el combate" (560d1) frente a otros deseos provistos de su propia apariencia de bien. Los deseos de la parte concupiscible, que se imponen en el caso del hombre democrático, no son fuerzas ciegas, sino deseos que, para interactuar con las demás partes en la unidad del alma, han de revestirse de apariencias del bien que los conviertan en valores en lugar de ser deseos descarnadamente irracionales.

Los deseos concupiscibles, para lograr sus propósitos, presentan el "pudor" como "idiotez" (560d2), "el control de sí mismo" como "falta de virilidad" (560d3), y la "moderación y la mesura en los gastos" como "rusticidad" y "servilismo" (560d4-5). Podríamos dar más ejemplos de este discurso de justificación ideológi-

\footnotetext{
32 Véase la nota 25 a este pasaje de la República (IV 429c) en la edición ya citada (en n.2), pp.562-3.

33 Campese, 1998, p. 262, ve en la comida y la bebida, "paradigmas de acción explicables sin hacer referencia a las opiniones del agente sobre el bien".
} 
ca, que muestra cómo los deseos irracionales son capaces de presentarse como valores al revestirse de apariencias del bien para poder actuar en un escenario unitario del alma, en el que domina la volición sub specie boni. Son estrategias para justificar la legitimidad de los deseos, en las que vemos que las partes actúan en la unidad de la conciencia y son capaces de proveerse de representaciones y elementos cognitivos, que nos hablan de una parte racional proporcionando armas para el triunfo de lo concupiscible. En esta estrategia emprendida bajo la motivación de los deseos concupiscibles se produce el intento de denominar "eufemísticamente 'cultura' a la desmesura, 'liberalidad' a la anarquía, 'grandeza de espíritu' a la prodigalidad y 'virilidad' a la impudicia” (560e-561a). Eupaideusía, eleuthería, megaloprépeia y andreía no son ya deseos, sino valores reconocibles de la cultura griega. Son deseos que, bajo la cobertura de este procedimiento, se han provisto de imágenes del bien y otros elementos cognitivos para poder ejercer una función persuasiva en la unidad del alma en la que han de concurrir con otros deseos que se opongan a ellos. No hay que concebir las partes del alma como homunculi, como si cada una de ellas estuviera provista de una propia facultad racional, pues todas forman parte de la unidad de la conciencia, en la que los deseos concupiscibles son capaces de "apoderarse de la acrópolis del alma" (560b7-8) y ponerla al servicio de sus propias motivaciones.

En el paso del hombre oligárquico al democrático, los deseos concupiscibles son capaces de poner al servicio de sus intereses lo que en la unidad del alma puede parecer una tarea ética amparada en valores y apariencias del bien. En consecuencia, después de todo, la irracionalidad del deseo no se revela tan incompatible con el intelectualismo del viejo Sócrates, para quien el hombre siempre actúa sub specie boni. Pero para bien de una ordenación racional del alma, también puede ocurrir lo contrario, es decir, que las otras partes sean domesticadas e impedidas de interferir las unas contra las otras en "una armonía" en la que las tres convivan dentro del orden trazado por la inteligencia (443d-e). Es la situación del alma justa que logra "la unidad absoluta, moderada y armónica" (443e). En este caso ideal, "cuando el alma íntegra sigue a la parte filosófica sin disensiones internas" (586e), puede suceder no ya que los deseos concupiscibles se conviertan en valores aparentes, sino que los verdaderos valores en un alma integrada sean capaces de actuar sobre los deseos gracias a la labor educativa. Esta posibilidad, en la que los deseos son transformados por valores que son capaces de reorientarlos, concediéndoles una satisfacción que no sea incompatible con la visión del bien que se contempla en la unidad del alma, es una empresa cognitiva, ${ }^{34}$ que debe permitir una volición unitaria e integrada en la que, efectivamente, todo lo hace el alma en aras del bien.

\footnotetext{
34 Sobre la naturaleza cognitiva de esta empresa de conversión o reorientación de los deseos, cfr. Kahn, 1987, p. 101.
} 
Puede ocurrir, sin embargo, que esto no se logre y persistan partes del alma con deseos adheridos a sus objetos propios. Es la situación en la que "otros malos apetitos" persisten en el individuo y éste no puede "persuadirlos de que no son lo mejor ni dulcificarlos por el razonamiento, sino mediante la coerción y el miedo" (554d). En esos casos, como dice Platón a propósito del hombre oligárquico, esta persona "no carecerá de disensiones en su interior, por no ser un solo hombre sino dos" (554d9-10) y, por tanto, "la verdadera excelencia de un alma concorde y armónica huirá lejos de él". La unidad integrada del alma supone una concordia en la volición en la que las partes han sido llevadas a coincidir en su apreciación del objeto que desean y no se consigue, por el contrario, cuando los deseos en las partes siguen adheridos a objetos propios que se oponen a una común apreciación. Esto es lo que describe la República: un alma capaz de obrar en todo por su deseo del bien, aunque sea en ocasiones equivocadamente arrastrada por falsas apariencias, y unos deseos que pueden coincidir con esta potencia del bien que reside en toda alma, pero que también pueden oponérsele. La relación entre el mero deseo y el valor habla de dos operaciones inversas, pero ambas posibles en las aventuras de la virtud y el vicio: cuando el valor sabe convertirse en objeto apetecible para las partes irracionales y cuando los deseos logran revestirse de apariencias del bien, para convertirse en valores que les hace ser aceptables en la economía unitaria del alma. Más lejos no nos permite llegar el texto de la República.

Si queremos reconciliar esta descripción con el Banquete, sería tentador suponer en la unidad del alma que actúa buscando siempre el bien esa misma boúlēsis que, en esta última obra, venía a coincidir con el deseo del bien perseguido universalmente por todos los hombres y en toda ocasión. Nada de ello se dice en la República. Pero los hechos de los que la psicología de esta obra dan testimonio apuntan a un alma que en la unidad de su conciencia, para actuar, necesita proveerse de estas imágenes del bien que operan sobre la voluntad. En un escalón inferior, aparecen los deseos como fuerzas motivadoras, a veces irracionalmente opuestas a lo más conveniente, pero para poder hacer valer sus derechos y prevalecer sobre deseos opuestos, tienen que persuadir a una potencia que solo puede operar llevada por la apariencia del bien. En la República no se habla de esta boúlēsis: nada impide que su lugar pudiera ocuparlo la misma razón en tanto que dotada ella misma de una voluntad de bien. De acuerdo con el principio de los opuestos, lo que no es posible es la existencia de una misma volición dividida con motivaciones opuestas, sino potencias volitivas diferentes, que coexisten entre sí. A mi modo de ver, Platón, como hemos visto en el Banquete, no tiene todavía un término claro para la voluntas, pues habla indistintamente de deseo, amor y volición. Probablemente en lo que la anticipa, al entrever que el alma decide siempre sub specie boni, aún no la distingue tampoco claramente de la razón o al menos no la concibe autónomamente, capaz de enfrentarse a ella. Pero la diferencia trazada entre el mero deseo y el valor, que permite al apetito operar en la unidad del alma bajo el deseo del bien, parece 
apuntar a un rasgo claro del concepto de voluntad. A ello parece contraponerse la mera potencia volitiva del deseo, que es capaz de oponerse a él, aunque también sea susceptible de ser reconducida a concordar con ella en un alma integrada y verdaderamente virtuosa. En el Banquete la boúlēsis como deseo del bien no se identifica, sin embargo, con la razón y, como observamos en el texto citado (204d), es capaz de proponerse como objetos elementos que no son los propios del deseo racional. En la República no se habla expresamente de la boúlēsis, sino de partes del alma con sus propios deseos, pero la distinción entre el mero deseo y el valor, junto al hecho de que el alma hace todo lo que hace en aras del bien, parece apuntar a una dimensión unitaria del alma, más o menos determinada por la racionalidad, que opera siempre sub specie boni, distinta del poder volitivo de las partes, ocasionalmente enfrentado a ella. El tema de si esta potencia volitiva del alma unitaria es diferente de la misma razón, dado que esta también alberga deseos, no parece resolverse explícitamente en la obra. En un alma que alcanza la verdadera virtud, se dice, "el alma íntegra sigue a la parte filosófica sin disensiones internas" (586e), con lo cual parece privilegiarse a la razón en tanto que potencia dotada de una voluntad de bien. Sería ello un anticipo en cierto modo de la boúlēsis aristotélica cuando el Estagirita afirma que esta se "origina en la parte racional" (De An. 432b5) o que constituye "un deseo que mueve en concordancia con el razonamiento" (433a23-24).

En cualquier caso, a mi juicio no creo que podamos hablar de un abandono total del intelectualismo socrático, ya que, por un lado, se reconocen deseos independientes del bien, pero, por otro lado, también se describe a la vez la necesidad que tienen estos de proveerse de apariencias e imágenes del bien. Esto significa que subyace una potencia volitiva solo capaz de actuar en aras del bien: todo dependerá en definitiva del poder intelectivo que pueda proveer la identificación del objeto del deseo con la apariencia o la realidad del bien. En consecuencia acertar o errar en la vida moral dependerá del poder determinante de la inteligencia a la hora de acertar con el bien o dejarse confundir por el poder ilusorio de las imágenes. Si el objeto de la boúlēsis es el bien, como dice Aristóteles (E.Nic. 1113a24), "para el hombre bueno será lo que en verdad lo es y para el malo cualquier cosa" (1113a25-6) que se lo parezca. La voluntad en Platón no se ha revelado todavía desde luego como en Agustín como una potencia autónoma y completamente diferenciada de la racionalidad, que pueda actuar a sabiendas en contra del bien y ni siquiera recorta aún claramente su silueta con una clara distinción de lo teórico y lo propiamente volitivo. Pero a mi juicio en los diálogos de Platón hay rasgos que apuntan a este concepto unas veces, como en el Banquete, de forma expresa y otras veces de forma implícita, como creo que ocurre en la República, cuando se alude a una formalidad genérica bajo la que debe actuar el deseo si quiere prevalecer en la concurrencia de motivaciones que compiten en los dominios del alma. 


\section{Referencias bibliográficas}

AdAm, J. (1902): The Republic of Plato, 2 vols., Cambridge.

AnNAS, J. (1981): An Introduction to Plato's Republic, Oxford.

Bobonich, C. (2002): Plato's Utopia Recast: His Later Ethics and Politics, Oxford.

Burnyeat, M.F. (2006): "The Truth of Tripartion", Proceedings of the Aristotelian Society 106, 1-23.

CAmpese, S. (1998): "Epithymia/epithymetikon", en Platone: La Repubblica, trad. e commento a cura di M.Vegetti, vol. III, Nápoles, 245-286.

Cooper, J.M. (2001): "Plato' s Theory of Human Motivation”, en E.Wagner (ed.), Essays on Plato's Psychology, Oxford, 91-114.

Crombie, I.M. (1979): Análisis de las Doctrinas de Platón, 2 vols., Madrid.

Delcomminette, S. (2008): "Facultes et parties de l'âme chez Platon", en Plato,

The Internet Journal of the International Plato Society, 8, 1-39.

EgGers, C. (2012): Platón, República, trad. de C.Eggers, intr. y notas de Á.Vallejo Campos, Milán.

FERBER, R. (2013): "Ho de diôkei men hapasa psychê kai toutou heneka panta prattei”, en Notomi \& Brisson (2013), 233-241.

FERRARI, G.R.F. (2007): "The Three Part Soul” en The Cambridge Companion to Plato's Republic, Cambridge, 165-201.

Fronterotta, F. (2013): "Plato' s Pyschology in Republic IV and X: how many parts of the soul" en Notomi \& Brisson (2013), 168-178.

GiLl, C. (2013): "What is the point of the Tripartite Psyche in Plato's Republic?, en Notomi \& Brisson (2013), 161-167.

IRwin, T.H. (1977): Plato's Moral Theory, The Early and Middle Dialogues, Oxford.

Irwin, T.H. (2000): La Ética de Platón, México (1995).

KaHN, C. (1987): "Plato's Theory of Desire", Review of Metaphysics, XLI, 77-103. Lorenz, H. (2004): "Desire and Reason in Plato' s Republic", Oxford Studies in Ancient Philosophy, 27, 83-116.

Lorenz, H. (2006): The Brute Within, Appetitive Desire in Plato and Aristotle, Oxford.

Lorenz, H. (2008): "Plato on the soul", en Fine, G. (ed.), The Oxford Handbook of Plato., Oxford, 243-266.

Migliori, M. (2013): Il Disordine Ordinato, La Filosofia Dialettica di Platone, vol.II Dall' anima alla prasi etica e politica, Brescia.

Miller, F. (1999): "Plato on the parts of the soul", en J.van Ophuijsen (ed) Plato and Platonism, Washington, 84-101.

NAtorP, P. (1999): Dottrina Platonica delle Idee. Una Introduzione all'Idealismo, Milán. 
Notomi, N. \& Brisson, L. (eds.) (2013): Dialogues on Plato's Politeia, Sankt Augustin.

Penner, T. (1978): "Thought and Desire in Plato", in G.Vlastos, Plato, A Collection of Critical Essays, 2 vols., Notre Dame, vol.II, 96-118.

PRICE, A.W. (1995): Mental Conflict, Londres.

Price, A.W. (2009): “Are Plato's Soul-Parts Psychological Subjects?”, Ancient Philosophy XXIX, 1-15.

Robinson, R. (1971): "Plato's separation of reason and desire", Phronesis 16, 3848.

Rowe, C. (2005): "Les Parties de l'âme et le désir du bien dans la République", en M.Dixsaut (ed.), Études sur la République de Platon, París, vol.2, 209-223.

Rowe, C. (2007): "The Place of the Republic in Plato's Political Thought", in G.R.F. Ferrari, The Cambridge Companion to Plato's Republic, Cambridge, 27-54.

Rowe, C. (2011): "The Treatment of the soul in Republic IV: exactly what does the "shorter" (435c-d) way miss?", en M. Migliori y otros (eds.), Inner Life and Soul, Pyschē in Plato, Sankt Augustin, 225-231.

SHIELDS, C. (2001): "Simple Souls" en E.Wagner, 137-156.

ShOREY, P. (1969): The Republic, 2 vols., Cambridge, Mass.

Stalley, R. (1975): "Plato's argument for the division of the reasoning and the appetitive elements within the soul", Phronesis 20, 110-128.

Vallejo, A. (2007): "Platón y la Academia", en Historia Universal del Pensamiento Filosófico, Ortuella.

Vallejo, A. (2009): "Platón y la teoría cognitiva del deseo", en V. Domínguez (ed.), La Oscuridad Radiante, Madrid-Oviedo, 113-136.

Vallejo, A. (2011): "The images of the Good and the interior life of the soul", en M.Migliori y otros (eds.), Inner Life and Soul, Pyschē in Plato, Sankt Augustin, 299-306.

Vallejo, A. (2013): "The Theory of Conflict in Plato's Republic", en N.NotomiL.Brisson (eds,), 192-198.

Vegetti, M. (1998): Platone. La Repubblica. Traduzione e commento a cura di M.Vegetti, vol. III, Libro IV, Nápoles.

Wagner, E. (ed.) (2001): Essays on Plato's Psychology, Lanham.

Álvaro Vallejo Campos

Departamento de Filosofía II

Facultad de Psicología

Universidad de Granada

avallejo@ugr.es 